\title{
ÉPOCA DE COLHEITA E SECAGEM NA QUALIDADE DE SEMENTES DE PIMENTA HABANERO YELLOW
}

\author{
LEIDIANE APARECIDA FERREIRA QUEIROZ2; ÉDILA VILELA DE RESENDE VON PINHO; \\ JOÃO ALMIR OLIVEIRA ${ }^{3}$; VALQUÍRIA DE FÁTIMA FERREIRA4; BRUNO OLIVEIRA CARVALHO;; \\ ANA CAROLINA ROSA BUENO5;
}

\begin{abstract}
RESUMO - As pimentas constituem um dos principais produtos da olericultura brasileira. O interesse das indústrias por espécies picantes, como a pimenta Habanero, tem crescido a cada ano, sobretudo para a produção de molhos e preparados desidratados, o que aumentou a demanda no mercado por sementes de qualidade. O autor teve, através desta pesquisa, por objetivo avaliar os efeitos das épocas de colheita das sementes e da secagem na qualidade das sementes de pimenta Habanero Yellow. Foram utilizadas sementes extraídas de frutos em quatro épocas de colheita (E1 - 50, E2 - 60, E3 - 67 e E4 - 67 DAA e mantidos em repouso por 7 dias após a colheita). As sementes extraídas dos frutos em diferentes épocas de colheita foram submetidas a quatro métodos de secagem: secagem artificial, aos $45^{\circ} \mathrm{C}$, até $8 \%$ de teor de água; secagem artificial, aos $35{ }^{\circ} \mathrm{C}$, até $20 \%$ de teor de água, seguida de secagem aos $45{ }^{\circ} \mathrm{C}$, até $8 \%$ de teor de água; secagem artificial, aos $35{ }^{\circ} \mathrm{C}$, até $8 \%$ de teor de água; e secagem natural à sombra até $8 \%$ de teor de água). A qualidade fisiológica das sementes antes da secagem foi avaliada por meio dos testes de germinação, emergência e envelhecimento acelerado, além da análise das isoenzimas esterase, superóxido dismutase, peroxidase, malato desidrogenase, álcool desidrogenase e da endo- $\beta$-mananase. Após a secagem, a qualidade fisiológica das sementes foi avaliada por meio dos testes de germinação, emergência e deterioração controlada. A qualidade fisiológica das sementes é máxima aos 67 DAA, quando os frutos estão completamente maduros. Maiores valores de germinação e vigor são observados em sementes secadas aos $35^{\circ} \mathrm{C}$.
\end{abstract}

Termos para indexação: Capsicum chinense Jacquin, formação de sementes, enzimas, vigor de sementes.

\section{INFLUENCE OF MATURATION STAGE AND DRYING ON THE QUALITY OF 'HABANERO YELLOW' PEPPER SEEDS}

\begin{abstract}
Peppers are widely grown in Brazilian horticulture. The interest of food industries in spicy species, such as 'Habanero' pepper, has steadily increased, especially for producing sauces and dehydrated condiments. Consequently, industrial demand for quality seeds has risen considerably. The objective of this research was to evaluate the effects of seed harvest timing and drying on the quality of 'Habanero Yellow' pepper seeds. The seeds were harvested from
\end{abstract}

\footnotetext{
${ }^{1}$ Submetido em 12/09/2010. Aceito para publicação em 08/02/2011. Parte da Tese de Doutorado do primeiro autor apresentada a (UFLA), Universidade Federal de Lavras-MG.

${ }^{2}$ Eng. Agrônoma. Fiscal Federal Agropecuária do Mapa. Caixa postal 163, Campus Histórico da UFLA. 37200-000 - Lavras - MG. E-mail: leidiane.queiroz@agricultura.gov.br

${ }^{3}$ Prof. Associado, Depto. de Agricultura, UFLA, Caixa postal 3037, 37200000 - Lavras - MG. E-mail: edila@dag.ufla.br; jalmir@dag.ufla.br
}

${ }^{4}$ Estudante de Pós-Graduação, Depto. de Fitotecnia, UFLA, Caixa postal 3037, 37200-000 - Lavras - MG. E-mail: ffval@yahoo.com.br; brunoagroufla@hotmail.com

${ }^{5}$ Estudante de Pós-Graduação, Depto. de Fisiologia Vegetal. Instituto Agronômico de Campinas, Caixa postal 28, Centro de Ecofisiologia e Biofísica. Av. Barão de Itapura, 1481, Botafogo, 13001-970- Campinas - SP. E-mail: anacarolina_rosabueno@hotmail.com 
fruits at four different times (E1 - 50; E2 - 60 ; E3 - 67 ; E4 - 67 days after anthesis-DAA) and were stored for 7 days after harvesting. These seeds were submitted to four drying methods: artificial drying at $45^{\circ} \mathrm{C}$ until $8 \%$ water content; artificial drying at $35^{\circ} \mathrm{C}$ until $20 \%$ water content followed by drying at $45^{\circ} \mathrm{C}$ until $8 \%$ water content; artificial drying at $35{ }^{\circ} \mathrm{C}$ until $8 \%$ water content; and natural drying under shade until $8 \%$ water content. The physiological quality of seeds before drying was evaluated from germination, emergence and accelerated aging tests, besides isozymes analyses (esterase, superoxide dismutase, peroxidase, malate dehydrogenase, alcohol dehydrogenase and endo- $\beta$-mannanase). After drying, the physiological quality of the seeds was evaluated from germination, emergence and controlled deterioration tests. The highest physiological quality of the seeds was at $67 \mathrm{DAA}$, when the fruits were completely ripe. The highest values for germination and vigor were observed for seeds dried at $35^{\circ} \mathrm{C}$.

Index terms: Capsicum chinense Jacquin, seed formation, enzymes, seed vigor.

\section{INTRODUÇÃO}

A pimenta Habanero é a mais brasileira de todas as espécies. É originária da região amazônica e é extremamente apreciada pelo seu sabor e picância inconfundíveis. Como as demais espécies de pimenta, a oferta de sementes de qualidade de pimenta Habanero é limitada, sobretudo pelo desconhecimento do melhor estádio de colheita das sementes e a utilização de métodos de secagem adequados, que visem aumentar o potencial de armazenamento e o estabelecimento de plantas no campo.

O melhor estádio de colheita de sementes está relacionado ao ponto de maturidade fisiológica, momento em que as sementes atingem o máximo acúmulo de matéria seca. Para a definição do ponto ideal de colheita, são de suma importância o conhecimento do processo de maturação dos frutos e sua associação ao desenvolvimento das sementes. Muitos marcadores são utilizados para a determinação da maturidade fisiológica das sementes, como a mudança de coloração dos frutos (Barbedo et al., 1994; Dias et al., 2006b), tamanho dos frutos, peso das sementes (Fessel et al., 2001; Dias et al., 2006a, b; Costa et al., 2006) e teor de água (Fessel et al., 2001; Araújo et al., 2006). A escolha do marcador dependerá do objetivo a ser alcançado.

Segundo Lakshmanan e Berke (1998), Bosland e Votava (1999) e Nascimento (1998), sementes recémcolhidas de espécies do gênero Capsicum podem apresentar dormência e Randle e Honma (1981) afirmaram que o genótipo e a idade do fruto influenciam a intensidade de dormência das sementes e que sementes extraídas de frutos supermaduros germinam mais rapidamente, havendo aumento da intensidade de dormência com o decréscimo da idade do fruto.

Além do momento de colheita adequado, a secagem das sementes é muito importante no controle de qualidade nas empresas produtoras, principalmente considerando o fato de que quando as sementes atingem o ponto de maturidade fisiológica, as mesmas se encontram com elevado teor de água. A secagem de sementes com elevado teor de água deve ser adotada de forma cuidadosa, para evitar danos com consequente perda de viabilidade e qualidade. A secagem inicial de sementes com elevado teor de água a altas temperaturas afeta processos metabólicos importantes na qualidade, tais como a conversão de glicose a sacarose e a produção de enzimas chaves da germinação, dentre outros (Faria et al., 2003).

Desse modo, conhecer o momento ideal de colheita e do método de secagem adequado para sementes de pimenta é de suma importância para garantir a máxima qualidade e vigor no campo.

Nesse contexto, objetivou-se, com a realização deste trabalho, avaliar o efeito da época de colheita dos frutos e da secagem na qualidade de sementes de pimenta Habanero Yellow, visando à máxima qualidade das sementes.

\section{MATERIAL E MÉTODOS}

A pesquisa foi conduzida no Laboratório Central de Sementes e na área experimental do Departamento de Agricultura da Universidade Federal de Lavras (UFLA), em Lavras, MG. A cidade está localizada na região sul de Minas Gerais, coordenadas $21^{\circ} 14^{\prime} \mathrm{S}$ de latitude e $40^{\circ} 17^{\prime} \mathrm{W}$ de longitude, a $918,8 \mathrm{~m}$ de altitude. Foram utilizadas sementes da variedade de pimenta Habanero Yellow 
(Capsicum chinense Jacquin). As sementes de pimenta foram semeadas em bandejas de isopor com 72 células, contendo substrato comercial Plantmax-hortaliças para a formação das mudas, que foram transplantadas para a área experimental, do Departamento de Agricultura, após 45 dias da semeadura.

O ensaio para a produção de sementes foi conduzido na área experimental do Departamento de Agricultura da UFLA, em Latossolo Vermelho-Escuro (LE), textura argilosa, preparado convencionalmente. $\mathrm{O}$ transplantio das mudas foi realizado na segunda quinzena do mês de dezembro. Cada parcela foi composta de 2 linhas de $11 \mathrm{~m}$ de comprimento, com 11 plantas, espaçadas $1,5 \mathrm{~m}$ entre linhas.

As adubações, assim como os demais tratos culturais, foram realizados de acordo com as recomendações para a cultura (Filgueira, 2003).

Utilizou-se o delineamento em blocos casualizados (DBC) com quatro repetições, tendo os frutos sido colhidos em quatro épocas de colheita, em cada bloco: E1 (50 dias após a antese, ou DAA; frutos completamente verdes), E2 (60 DAA; frutos com os primeiros sinais de amarelecimento), E3 (67 DAA; frutos maduros, caracterizados pela cor laranja) e E4 (67 DAA; frutos maduros, caracterizados pela cor laranja, mantidos em repouso por 7 dias após a colheita).

As sementes foram extraídas manualmente com o auxílio de um estilete. Após a extração, as sementes foram desinfestadas com solução $1 \%$ de hipoclorito de sódio, por um minuto. Em seguida procedeu-se à instalação dos testes para avaliação da qualidade das sementes.

Parte das sementes extraídas de frutos em diferentes épocas de colheita foi submetida a quatro métodos de secagem: M1 (secagem artificial, aos $45^{\circ} \mathrm{C}$, até $8 \%$ de teor de água), M2 (secagem artificial, aos $35^{\circ} \mathrm{C}$, até $20 \%$ de teor de água e seguida de secagem aos $45^{\circ} \mathrm{C}$, até $8 \%$ de teor de água), M3 (secagem artificial, aos $35{ }^{\circ} \mathrm{C}$, até $8 \%$ de teor de água) e M4 (secagem natural à sombra, até $8 \%$ de teor de água). Foram utilizados secadores de pequena escala, construídos de acordo com Novratil e Burris (1982). Os secadores foram regulados para as temperaturas constantes de $35^{\circ} \mathrm{C}$ e $45^{\circ} \mathrm{C}$.

Após a secagem, as sementes foram acondicionadas em embalagens impermeáveis de alumínio e armazenadas em câmara fria aos $10^{\circ} \mathrm{C}$ e $55 \%$ de umidade relativa, até as avaliações da qualidade fisiológica.

A qualidade fisiológica das sementes foi avaliada antes da secagem por meio dos testes de germinação, de emergência e envelhecimento acelerado. Após a secagem, a qualidade das sementes foi avaliada pelos testes de germinação, emergência e deterioração controlada.

O teor de água das sementes foi avaliado em estufa, a $105 \pm 3{ }^{\circ} \mathrm{C}$, durante 24 horas, utilizando-se duas subamostras para cada tratamento, conforme as Regras para Análise de Sementes - RAS (Brasil, 2009). Os resultados foram expressos em porcentagem média por tratamento.

No teste de germinação, a semeadura foi realizada sobre duas folhas de papel para germinação em caixas, umedecidas com água, na proporção de três vezes o peso do substrato seco, em caixas plásticas tipo gerbox. As caixas foram mantidas em germinadores sob regime alternado de temperatura e luz $\left(20^{\circ} \mathrm{C} / 16\right.$ horas no escuro e $30{ }^{\circ} \mathrm{C} / 8$ horas na presença de luz). Aos 7 e 14 dias, procedeu-se a avaliação, segundo Brasil (2009). Cada tratamento foi composto de quatro subamostras de 50 sementes. Os resultados foram expressos em porcentagem de plântulas normais.

As sementes que não germinaram foram submetidas ao teste de tetrazólio. Estas foram imersas para coloração em solução de 2,3,5 trifenil cloreto de tetrazólio a aproximadamente $0,075 \%$, durante 3 horas, no escuro, aos $35^{\circ} \mathrm{C}$. Após este período, verificado a coloração ideal, as sementes foram lavadas em água corrente e mantidas submersas em água até sua avaliação. Na segunda etapa, os embriões foram analisados individualmente, após abertura com uma lâmina cirúrgica no sentido longitudinal, verificando-se sua face externa e interna. A interpretação foi feita com auxílio de lupa com iluminação fluorescente, de acordo com as RAS (Brasil, 2009), para verificar se as sementes estavam mortas.

No teste de deterioração controlada, inicialmente, o teor de água das sementes foi elevado para $24 \%$ de água, por meio do método da atmosfera úmida (Rosseto et al., 1995). Para isso, amostras de 200 sementes foram acondicionadas sobre tela metálica em caixas plásticas tipo gerbox com $40 \mathrm{~mL}$ de água destilada no fundo. Essas caixas, tampadas, foram mantidas em incubadora, a 20 ${ }^{\circ} \mathrm{C}$. Durante o umedecimento artificial, os teores de água foram monitorados por meio de pesagens sucessivas com intervalos de duas horas, sendo na última hora realizadas em intervalos de 15 minutos, até a obtenção do teor de água desejado. Numa segunda etapa, as sementes com $24 \%$ de teor de água foram deterioradas por 24 horas aos $45^{\circ} \mathrm{C}$ (Ilbi et al., 2008). Em seguida, procedeu-se o teste de germinação com quatro subamostras de 50 sementes 
(Brasil, 2009). Foram avaliadas as porcentagens de plântulas normais aos 7 e aos 14 dias após a semeadura (Torres, 2005).

No teste de emergência, a semeadura foi realizada em bandejas multicelulares de isopor com células separadas, contendo substrato comercial (Plantmax-hortaliças). As bandejas foram mantidas em casa de vegetação dotada de sistema de nebulização intermitente, à temperatura de 25 ${ }^{\circ} \mathrm{C}$ a $30{ }^{\circ} \mathrm{C}$. Para cada tratamento foram utilizadas quatro subamostras de 50 sementes. Foram realizadas avaliações diárias a partir do início da emergência, computando-se o número de plântulas emersas até a estabilização do estande. Foi computada a porcentagem de plântulas normais aos 30 dias.

Para o teste de envelhecimento acelerado foram utilizadas caixas plásticas tipo gerbox, em incubadora por 72 horas, aos $38^{\circ} \mathrm{C}$. Decorrido esse período de envelhecimento, 4 subamostras de 50 sementes por tratamento foram colocadas para germinar, conforme a metodologia descrita para o teste de germinação. A avaliação foi realizada aos 14 dias após a semeadura. Os resultados foram expressos em porcentagem média de plântulas normais para cada tratamento (Torres, 2005).

Para a análise das enzimas, duas amostras de sementes de cada tratamento foram maceradas em mortar com nitrogênio líquido. Foram retiradas subamostras de $100 \mathrm{mg}$, às quais se adicionou o tampão de extração (Tris $\mathrm{HCl} 0,2 \mathrm{M}$ $\mathrm{pH} 8$ ) na quantidade de 2,5 vezes o peso de cada amostra e $0,1 \%$ de $\beta$-mercaptoetanol. O material foi mantido em geladeira over night e depois, foi centrifugado a $14.000 \mathrm{xG}$, por 30 minutos, aos $4{ }^{\circ} \mathrm{C}$. A corrida eletroforética foi no sistema de géis de poliacrilamida em 7,5\% (gel separador) e 4,5\% (gel concentrador). O sistema gel/eletrodo utilizado foi o Tris-glicina $\mathrm{pH}$ 8,9. Foram aplicados $50 \mu \mathrm{L}$ do sobrenadante das amostras no gel e a corrida eletroforética foi efetuada a $120 \mathrm{~V}$ por 5 horas.

As enzimas esterase, superóxido dismutase, peroxidase, malato desidrogenase e álcool desidrogenase foram reveladas de acordo com Alfenas et al. (2006).

Para a avaliação da atividade da enzima endo- $\beta$ mananase foram adicionados $300 \mu \mathrm{L}$ do tampão de extração (0,1 M Hepes; $0,5 \mathrm{M}$ de $\mathrm{NaCl} \mathrm{pH}$ 8,0; ácido ascórbico na proporção de $5 \mathrm{mg}$ do ácido para cada $\mathrm{mL}$ de tampão) em cada microtubo com $100 \mathrm{mg}$ de pó de cada amostra. Em seguida, os microtubos contendo as amostras foram agitados em agitador tipo vortex por 1 minuto e centrifugados, a $10.000 \mathrm{xG}$ por 30 minutos, aos $4{ }^{\circ} \mathrm{C}$. O sobrenadante foi aplicado em gel $(6 \mathrm{~mL}$ de locust bean gum, ou LBG -Sigma nr 0753); 0,24 g de agarose (Qbiogene); $24 \mathrm{~mL}$ de tampão $\mathrm{pH}$ 5,0 (11 mL de ácido cítrico $1 \mathrm{M}, 50 \mathrm{~mL}$ de $\mathrm{Na}_{2} \mathrm{HPO}_{4}$ e $149 \mathrm{~mL}$ de água destilada). O LBG $0,5 \%$ foi preparado aquecendo-se a solução por 2 horas, aos $80{ }^{\circ} \mathrm{C}$, seguido de resfriamento em temperatura ambiente.

Para o cálculo da atividade da enzima, foi feita uma comparação com a curva padrão gerada pela endo- $\beta$ mananase comercial de Aspergillus niger (Megazyme). $\mathrm{O}$ cálculo da atividade da enzima endo- $\beta$-mananase foi realizado segundo (Downie et al. 1994).

O delineamento experimental utilizado nos testes para a avaliação da qualidade das sementes de pimenta foi o de blocos casualizados, em esquema fatorial $4 \mathrm{x} 4$, cujos fatores foram épocas de colheita (E1, E2, E3 e E4) e método de secagem (M1, M2, M3 e M4).

Foi realizada a análise de variância para todos os testes, utilizando o programa estatístico Sisvar (Ferreira, 2000). Os dados em porcentagem foram transformados por $\sqrt{\mathrm{y}+0,5}-\operatorname{SQRT}(\mathrm{y}+0,5)$.

Para a comparação entre as médias, empregou-se o Teste de Scott-Knott, a 5\% de probabilidade. A avaliação dos padrões enzimáticos foi feita de acordo com a intensidade das bandas, utilizando-se a superfície de um transiluminador.

\section{RESULTADOS E DISCUSSÃO}

O efeito da época de colheita dos frutos foi significativo $(\mathrm{p}<0,05)$, pelo teste $\mathrm{F}$, em relação à germinação e ao vigor das sementes de pimenta Habanero (Tabela 1).

Os valores de teores de água em sementes colhidas em diferentes épocas de colheita variaram de $55 \%$ aos 67\% (Tabela 2). As porcentagens de germinação e de emergência de plântulas, das sementes colhidas 67 dias após a antese (DAA) e que ficaram em repouso nos frutos por sete dias (estádio E4) foram maiores que as daquelas colhidas aos 67 DAA, mas que não ficaram em repouso nos frutos (época E3); já as sementes colhidas em épocas iniciais de desenvolvimento, aos 50 e 60 DAA (épocas E1 e E2), respectivamente, praticamente não germinaram e a emergência também foi muito baixa (Tabela 2). Vale salientar que a emergência foi avaliada aos 30 dias, pois, aos 14 dias após a semeadura, nenhuma plântula havia emergido. Muitos autores têm observado em espécies de pimenta que a emergência das plântulas é lenta e irregular, mesmo sob condições favoráveis (Randle e Honma, 1981; Lakshmanan e Berke, 1998). 
TABELA 1. Resumo da análise de variância dos dados referentes à porcentagem de germinação (TG), emergência (TE) e germinação após a deterioração controlada (DC) de sementes de pimenta habanero yellow (Capsicum chinense Jacquin) colhidas em diferentes épocas de colheita e submetidas a diferentes métodos de secagem.

\begin{tabular}{ccccc}
\hline \multirow{2}{*}{ Fonte de variação } & GL & \multicolumn{3}{c}{ QM } \\
\cline { 3 - 4 } & & $145,817815^{*}$ & $283,780236^{*}$ & $261,901631^{*}$ \\
Épocas de colheita & 3 & 1,816188 & $4,822704^{*}$ & $1,827850^{*}$ \\
Secagem & 3 & 3,057570 & 0,616537 & 0,765056 \\
E x S & 9 & 2,349490 & 0,424726 & 0,251761 \\
Bloco & 3 & 3,564461 & 0,322392 & 0,428499 \\
Erro & 45 & 54,45 & 10,63 & 15,44 \\
\hline
\end{tabular}

* Teste de $\mathrm{F}$ significativo, a 5\% de probabilidade.

Belletti e Quagliotti (1989) relataram que é alta a porcentagem de sementes de pimenta que não germinam até 14 dias após a semeadura, podendo ser necessário um período de até 45 dias para que a maioria das sementes de um lote germine satisfatoriamente. Randle e Honma (1981) avaliaram sementes de 19 cultivares de pimenta e observaram que a emergência de plântulas ocorreu de 14 a 23 dias.

Provavelmente, as porcentagens reduzidas de germinação e emergência se devem à dormência das sementes, pois durante a avaliação do teste de germinação, foi observada a presença de sementes embebidas sem protrusão radicular. No entanto, essas sementes não estavam mortas, o que pôde ser constatado por meio do teste de tetrazólio. As sementes embebidas estavam viáveis, sem quaisquer sintomas de deterioração. Segundo Lakshmanan e Berke (1998), Bosland e Votava (1999) e Nascimento (1998), sementes recém-colhidas de espécies do gênero Capsicum podem apresentar dormência.

Randle e Honma (1981) afirmaram que o genótipo e a idade do fruto influenciam a intensidade de dormência das sementes e que sementes extraídas de frutos supermaduros germinam mais rapidamente, havendo aumento da intensidade de dormência com o decréscimo da idade do fruto.

O vigor das sementes, avaliado pelo teste de envelhecimento acelerado, foi maior para as sementes colhidas aos 67 DAA (E3 e E4); nas épocas E1 e E2, a germinação das sementes após o envelhecimento acelerado foi praticamente nula (Tabela 2).

Vale salientar que, nas épocas E1 e E2, as sementes provavelmente, ainda não haviam atingido a maturidade fisiológica. Logo, a ocorrência de dormência associada à imaturidade fisiológica das sementes fundamenta a germinação e o vigor reduzidos das sementes colhidas aos 50 e 60 DAA.

TABELA 2. Porcentagens de germinação (TG), emergência (TE), germinação após o envelhecimento acelerado (EA) e teor de água (U) de sementes de pimenta habanero yellow (Capsicum chinense Jacquin) colhidas em diferentes épocas de colheita (E1 - 50 DAA, E2 - 60 DAA, E3 - 67 DAA, E4 - 67 DAA + 7 dias de repouso).

\begin{tabular}{ccccc}
\hline Estádio & TG & TE & EA & U \\
\hline E1 & $3,0 \mathrm{c}$ & $1,0 \mathrm{c}$ & $0,0 \mathrm{c}$ & 67,0 \\
E2 & $4,0 \mathrm{c}$ & $4,0 \mathrm{c}$ & $4,0 \mathrm{c}$ & 59,0 \\
E3 & $48,0 \mathrm{~b}$ & $31,0 \mathrm{~b}$ & $29,0 \mathrm{~b}$ & 56,0 \\
E4 & $72,0 \mathrm{a}$ & $68,0 \mathrm{a}$ & $39,0 \mathrm{a}$ & 55,0 \\
\hline
\end{tabular}

*As médias seguidas pela mesma letra (na coluna) não diferem entre si, pelo teste de Scott Knott, a 5\% de probabilidade.

Já os maiores valores de germinação e vigor das sementes colhidas 67 DAA podem ser explicados pela maturidade fisiológica das mesmas. Quando as sementes atingem a maturidade fisiológica, são capazes de germinar e gerar plântulas normais, pois apresentam todos os aparatos químicos e fisiológicos necessários para tal. Resultados semelhantes foram observados por outros 
autores (Sanchez et al., 1993; Demir, 2002; Vidigal, 2009).

Segundo Nascimento e Freitas (2006), em espécies cujas sementes estão contidas em frutos carnosos, como nas pimentas, os valores máximos de germinação, vigor e acúmulo de matéria seca ocorrem quando as sementes atingem a maturidade fisiológica. Do mesmo modo, Vidigal et al. (2009a; 2009b), ao estudar o processo de maturação de sementes de pimenta, variedade Amarela Comprida, observou que a maturidade fisiológica ocorreu aos 70 DAA, quando o teor de água das sementes era de $46 \%$ e que a qualidade fisiológica das sementes foi máxima entre 65 e 70 dias após a antese, quando os frutos estavam com a cor vermelha e vermelho-intensa, respectivamente.

Pela análise da enzima endo- $\beta$-mananase (Figura
1), pode-se ratificar que as sementes oriundas de frutos colhidos nas épocas E3 e E4 já haviam atingido a maturidade fisiológica, apresentando o completo desenvolvimento dos mecanismos enzimáticos envolvidos na germinação. A atividade dessa enzima, que é chave na germinação de sementes de pimenta, foi maior nas épocas mais avançadas de desenvolvimento. Em sementes de tomate, o amolecimento do endosperma está diretamente ligado ao aumento da atividade da enzima endo- $\beta$-mananase (Nonogakii et al., 1992). Por meio de resultados de pesquisas, supõe-se que o controle da germinação pelo tegumento é ativado pela combinação ou ação sucessiva de inúmeras proteínas modificadoras da parede celular, incluindo endo- $\beta-1,4-$ mananase e endo- $\beta$-1,3-glucanase (Hilhorst, 1995; Bewley, 1997; Bailly, 2004; Kucera et al., 2005).

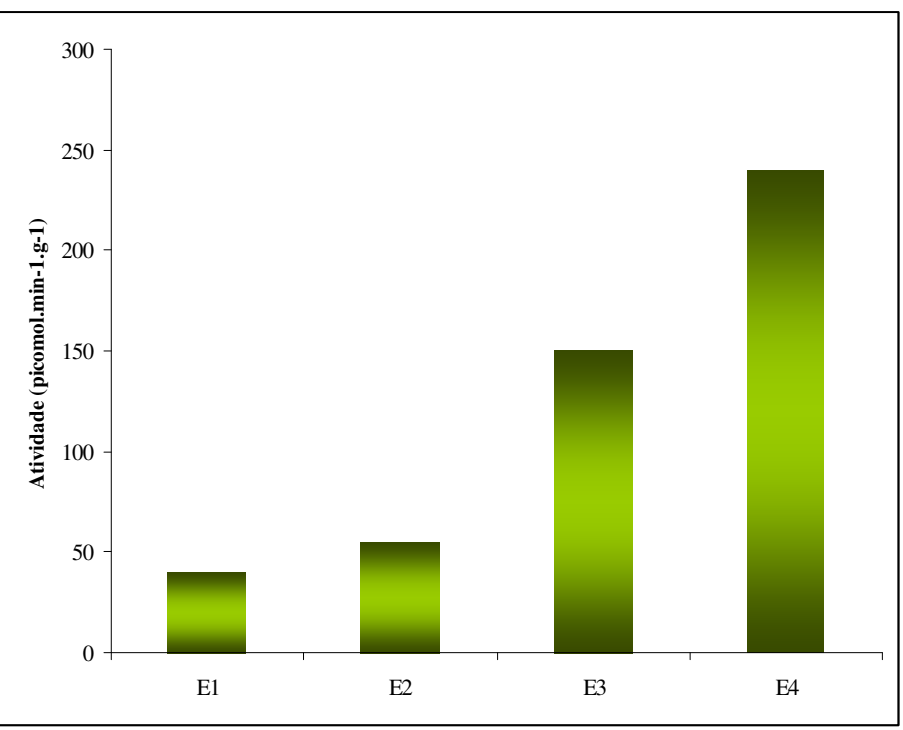

FIGURA 1. Atividade da enzima endo- $\beta$-mananase em sementes de pimenta Habanero nas épocas de colheita E1 (50 DAA), E2 (60 DAA), E3 (67 DAA) e E4 (67 DAA + 7 dias de repouso).

Por meio da análise dos padrões enzimáticos das sementes de pimenta Habanero, observou-se maior atividade da esterase nas épocas E1 e E2 (Figura 2). Essa maior atividade deve-se à imaturidade fisiológica das sementes. A esterase é uma enzima que participa da hidrólise de ésteres de membrana. Esse fato demonstra maior peroxidação de lipídios, uma vez que essa enzima está envolvida em reações de hidrólise de ésteres, estando diretamente ligada ao metabolismo de lipídios (Santos et al., 2004). Muitos desses lipídios são constituintes de membranas, cuja degradação aumenta com a desorganização do sistema de membranas.

Não foram observadas diferenças nos padrões enzimáticos da superóxido dismutase (SOD) e malato desidrogenase (MDH) das sementes colhidas nas quatro épocas.

Em relação à avaliação da qualidade das sementes após a secagem, o efeito da época de colheita dos frutos foi significativo $(p<0,05)$, pelo teste $F$, na germinação e no vigor das sementes de pimenta Habanero; já o efeito da secagem foi significativo $(p<0,05)$, pelo teste $F$, no vigor das sementes, não apresentando efeito sobre a germinação (Tabela 1). 


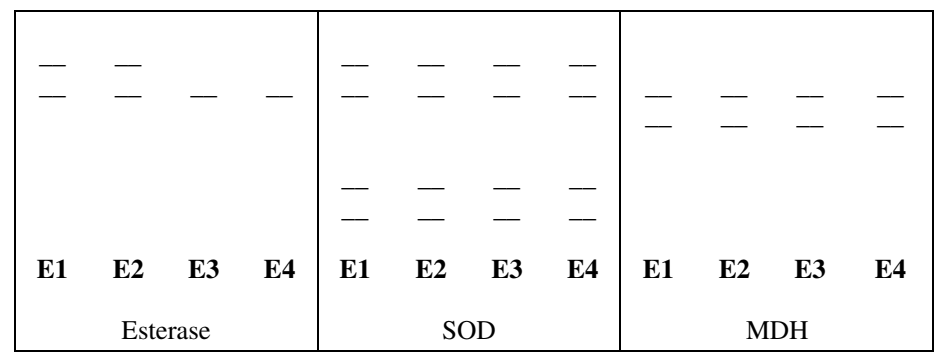

FIGURA 2. Padrões enzimáticos de sementes de pimenta Habanero Yellow colhidas em quatro épocas de colheita (E1 - 50 DAA, E2 - 60 DAA, E3 - 67 DAA, E4 - 67 DAA + 7 dias de repouso), revelados para a esterase (EST), superóxido dismutase (SOD) e malato desidrogenase (MDH).

Em concordância com os resultados obtidos antes da secagem, os maiores valores de germinação e vigor foram observados nas sementes colhidas aos 67 DAA (épocas E3 e E4) (Tabela 3). Nas épocas E1 e E2, 50 e 60 DAA, respectivamente, a germinação e o vigor foram praticamente nulos. Geralmente, frutos imaturos, de coloração verde, produzem sementes com baixo vigor e baixo poder germinativo ou até inférteis (Nascimento e Freitas, 2006).

TABELA 3. Porcentagem de germinação (TG), emergência (TE), germinação após a deterioração controlada (DC) e de teor de água (U) de sementes de pimenta habanero yellow (Capsicum chinense Jacquin) colhidas em diferentes épocas de colheita (E1 - 50 DAA, E2 - 60 DAA, E3 - 67 DAA, E4 - 67 DAA + 7 dias de repouso).

\begin{tabular}{ccccc}
\hline Estádio & TG & TE & DC & U \\
\hline E1 & $0,0 \mathrm{~b}$ & $1,0 \mathrm{~d}$ & $0,0 \mathrm{~b}$ & 67,0 \\
E2 & $1,0 \mathrm{~b}$ & $7,0 \mathrm{c}$ & $0,0 \mathrm{~b}$ & 59,0 \\
E3 & $40,0 \mathrm{a}$ & $76,0 \mathrm{~b}$ & $58,0 \mathrm{a}$ & 56,0 \\
E4 & $46,0 \mathrm{a}$ & $84,0 \mathrm{a}$ & $63,0 \mathrm{a}$ & 55,0 \\
\hline
\end{tabular}

*As médias seguidas pela mesma letra (na coluna) não diferem entre si, pelo teste de Scott Knott, a 5\% de probabilidade.

Barbedo et al. (1994) relataram que sementes de berinjela obtidas de frutos com 50 dias de idade devem ser submetidas a 15 dias de armazenamento pós-colheita para que atinjam qualidade fisiológica adequada. Resultado semelhante foi obtido por Sanchez et al. (1993), analisando sementes de pimentão colhidas aos $50 \mathrm{DAA}$. Após o período de repouso dos frutos por sete dias, foram observados maiores valores de emergência das plântulas, corroborando as conclusões de Randle e Honma (1981), de que sementes extraídas de frutos supermaduros germinam mais rapidamente e apresentam menor intensidade de dormência. Vale ressaltar que as sementes podem atingir a maturidade após a colheita dos frutos, quando estes passam por um período de descanso ou repouso que varia de 7 a 10 dias, em local fresco e ventilado, antes da extração das sementes. Neste caso, sementes imaturas ainda presentes no fruto completam o seu desenvolvimento, resultando em melhor qualidade fisiológica e maior rendimento (Dias, 2001).

No momento da secagem as sementes apresentavam elevados teores de água (Tabela 3) e foram secadas até $8 \%$ de teor de água por diferentes métodos. A secagem natural, à sombra, método M4 e a secagem artificial, aos $35{ }^{\circ} \mathrm{C}$, método $\mathrm{M} 3$, foram as mais efetivas, pois não afetaram negativamente o vigor das sementes (Tabela 4). Esses dois métodos empregados simularam uma secagem lenta. Segundo Marcos Filho (2005), durante a secagem natural das sementes no campo, as mesmas perdem água gradativamente, o que permite o desenvolvimento dos mecanismos de tolerância que as prepara para resistir às consequências da desidratação.

Já nos métodos de secagem artificiais, empregando temperaturas de $45{ }^{\circ} \mathrm{C}$ (métodos M1 e M2 - Tabela 4) foi observado menor vigor das sementes. A secagem inicial de sementes com elevado teor de água, a altas temperaturas, afeta processos metabólicos importantes na qualidade, tais como a conversão de glicose à sacarose, 
a produção de enzimas chaves da germinação, dentre outros (Faria et al., 2003). Além dos aspectos químicos, a secagem de sementes com elevados teores de água a altas temperaturas pode causar danos irreparáveis ao sistema de membranas, prejudicando o seu desempenho fisiológico, levando ao desenvolvimento de plântulas anormais (Faria et al., 2003). Mesmo com a utilização de uma pré-secagem aos $35^{\circ} \mathrm{C}$, até que as sementes atingissem $20 \%$ de teor de água, método $\mathrm{M} 2$, a posterior utilização de temperatura mais elevada, $45^{\circ} \mathrm{C}$, pode ter causado danos de secagem às sementes. A secagem rápida de sementes com elevado teor de água induz a processos oxidativos e à produção de radicais livres, que podem ser removidos por mecanismos enzimáticos, tais como superóxido dismutase (SOD), catalase (CAT) e enzimas do ciclo ascorbato-glutationa. A atividade dessas enzimas está relacionada à aquisição de tolerância à dessecação, como foi detectado por Bailly et al. (2001), em sementes de feijão e por Brandão Júnior (2000), em café.

TABELA 4. Porcentagem de germinação (TG), emergência (TE) e germinação após a deterioração controlada (DC) de sementes de pimenta Habanero Yellow (Capsicum chinense Jacquin.) submetidas a diferentes métodos de secagem (M1, M2, M3 e M4).

\begin{tabular}{cccc}
\hline Secagem & TG & TE & DC \\
\hline M1 & $20,0 \mathrm{a}$ & $36,0 \mathrm{~b}$ & $25,0 \mathrm{~b}$ \\
M2 & $21,0 \mathrm{a}$ & $38,0 \mathrm{~b}$ & $27,0 \mathrm{~b}$ \\
M3 & $27,0 \mathrm{a}$ & $44,0 \mathrm{a}$ & $33,0 \mathrm{a}$ \\
M4 & $19,0 \mathrm{a}$ & $50,0 \mathrm{a}$ & $36,0 \mathrm{a}$ \\
\hline
\end{tabular}

*As médias seguidas pela mesma letra (na coluna) não diferem entre si, pelo teste de Scott Knott, a 5\% de probabilidade.

\section{CONCLUSÕES}

As sementes de pimenta Habanero Yellow podem ser colhidas a partir de $67 \mathrm{DAA}$, quando os frutos estão completamente maduros.

A secagem artificial das sementes de pimenta Habanero Yellow pode ser conduzida à temperatura de $35^{\circ} \mathrm{C}$.

\section{AGRADECIMENTOS}

Agradeço à Universidade Federal de Lavras, aos professores e funcionários do Setor de Sementes, aos alunos de Iniciação Científica (CNPq e FAPEMIG) e a CAPES, por tornarem possível a execução desse trabalho.

\section{REFERÊNCIAS}

ALFENAS, A.C.; DUZI, A.; ZERBINI JÚNIOR, F.M.; ROBINSON, I.P.; MICALES, J.A.; OLIVERIA, J.R.; DIAS, L.A.S.; SCORTICHINI, M.; PEREIRA, M.C.B.; BONDE, R.B.; ALONSO, S.K.; JUNGHANS, T.G.; BRUNE, W.; Eletroforese e marcadores bioquímicos em plantas e microorganismos. 2.ed. Viçosa: Ed. UFV, 2006, 627p.

ARAÚJO, E.F.; SOFIATTI, V.; SILVA, R.F. Maturação de sementes de milho-doce: grupo super doce. Revista Brasileira de Sementes, v.28, n.2, p.69-76, 2006.

BAILLY, C. Active oxygen species and antioxidants in seed biology. Seed Science Research, n.14, p.93-107, 2004.

BAILLY, C.; AUDIGIER, C.; LADONNE, F.; WAGNER, M.H.; COSTE, F.; CORBINEAU, F.; CÔME, D. Changes in oligosaccharide content and antioxidant enzyme activities in developing bean seeds as related to acquisition of drying tolerance and seed quality. Journal of Experimental Botany, v.52, n.357, p.701-708, 2001.

BARBEDO, A.S.C.; ZANIN, A.C.W.; BARBEDO, C.J.; NAKAGAWA, J. Efeitos da idade e do período de repouso pós-colheita dos frutos sobre a qualidade de sementes de berinjela. Horticultura Brasileira, v.12, n.1, p.18-21, 1994.

BELlETTI, P.; QUAGLIOTTI, L. Problems of seed production and storage of pepper. In: Tomato and pepper productions in the topics. Taipei: Asian Vegetable Research and Development Center, 1989. p.28-41.

BEWLEY, J.D. Seed Germination and dormancy. The Plant Cell, v.9, p.1055-1066, 1997.

BOSLAND, P.W.; VOTAVA, E.J. Peppers: vegetable and spice capsicums. Wallingford: CAB International, 1999. 204p. (Crop Production Science in Horticultire, 12).

BRANDÃO JÚNIOR, D. da S.; VIEIRA, M.G.G.C.; GUIMARÃES, R.M.; HILHORST, H. W.M. Tolerância à dessecação de sementes de cafeeiro (Coffea arabica L.). Revista Brasileira de Sementes, v. 24, n.2, p.17-23, 2002.

BRASIL. Ministério da Agricultura, Pecuária e Abastecimento. Regras para análise de sementes. Ministério da Agricultura, Pecuária e Abastecimento. 
Secretaria de Defesa Agropecuária. Brasília, DF: Mapa/ ACS, 2009. 395p.

COSTA, C.J.; CARMONA, R.; NASCIMENTO, W.M. Idade e tempo de armazenamento de frutos e qualidade fisiológica de sementes de abóbora híbrida. Revista Brasileira de Sementes, v.28, n.1, p.127-132, 2006.

DEMIR, I. The effect of controlled hydration treatment on germination and seedling emergence of unaged and aged pepper seeds during development. Israel Journal of Plant Sciences, v.50, n.4, p.251-257, 2002.

DIAS, D.C.F. Maturação de sementes. Seed News, v.5, n.6, p.22-24, 2001.

DIAS, D.C.F.S.; RIBEIRO, F.P.; DIAS, L.A.S.; SILVA, D.J.H.; VIDIGAL, D.S. Maturação de sementes de tomate em função da ordem de frutificação na planta. Revista Ceres, v.53, n.308, p.446-456, 2006 a.

DIAS, D.C.F.S.; RIBEIRO, F.P.; DIAS, L.A.S.; SILVA, D.J.H.; VIDIGAL, D.S. Tomato seeds quality in relation to fruit maturation and post-harvest storage. Seed Science and Technology, v.34, n.3, p.691-699, 2006b.

DOWNIE, B.; HILLHORST, H.W.M.; BEWLEY, J.D.A new assay for quantifying endo- $\beta$-mananase activity using Congo Red dye. Phytochemistry, v.36, p.829-835, 1994.

FARIA, M.A.V. de R.; PINHO, R.G. von; PINHO, E.V. de R. von; GUIMARÃES, R.M. Marcadores moleculares da qualidade fisiológica de sementes. Lavras: UFLA/ FAEPE, 2003.

FERREIRA, D.F. Análises estatísticas por meio do SISVAR para Windows ${ }^{\circledR}$ versão 4.0. In: REUNIÃO ANUAL DA REGIÃO BRASILEIRA DA SOCIEDADE INTERNACIONAL DE BIOMETRIA, 45., 2000, São Carlos. Programas e resumos... São Carlos: UFSCar, 2000. p.235.

FESSEL, S.A.; VIEIRA, R.D.; MENDONÇA, E.A.F.; CARVALHO, R.V. Maturação fisiológica de sementes de milho. Revista Brasileira de Sementes, v.23, n.1, p.191197, 2001.

FILGUEIRA, F.A.R. Solanáceas: agrotecnologia moderna na produção de tomate, batata, pimentão, pimenta, berinjela e jiló. Viçosa, MG: UFV, 2003. 333p.

HILHORST H.W.M. A critical update on seed dormancy. I. Primary dormancy. Seed Science Research, v.5, p.6173, 1995.

ILBI, H.; KAVAK, S.; ESER, B. Controlled deterioration test determines vigour and predicts field emergence in pepper seed lots. Seed Science and Technology, v.36, n.2, p.456-461, 2008.

KUCERA, B.; COHN, M.A.; LEUBNER-METZGER, G. Plant hormone interactions during seed dormancy release and germination. Seed Science Research, n.15, p.281-307, 2005.

LAKSHMANAN, V.; BERKE, T.G. Lack of primary seed dormancy in pepper (Capsicum spp.). Capsicum and Eggplant Newsletter, v.17, p.72-75, 1998.

MARCOS FILHO, J.M. Fisiologia de sementes de plantas cultivadas. Piracicaba: FEALQ, 2005. 496p.

NASCIMENTO, W.M. Condicionamento osmótico de sementes de hortaliças: potencialidades e implicações. Horticultura Brasileira, v.16, n.12, p.106-109, 1998.

NASCIMENTO, W.M.; FREITAS, R.A. Produção de sementes de pimentas. In: RIBEIRO, C. S. C.; HENZ, G. P.; CARVALHO, S.I.C.; LOPES, C. A. (Org.). Cultivo de pimentas (Capsicum spp.) no Brasil. Brasília: Embrapa Hortaliças, 2006. p.30-39.

NONOGAKI, H.; MATSUSHIMA, H.; MOROHASHI, Y. Galactomannan hydrolyzing activity develops during priming in the micropylar endosperm tip of tomato seeds. Physiologia Plantarum, v.85, n.2, p.167-172, 1992.

NOVRATIL, R.J.; BURRIS, J.S. Small-scale dryer designer. Agronomy Journal, v.74, n.1, p.159-161, 1982.

RANDLE, W.M.; HONMA, S. Dormancy in peppers. Scientia Horticulturae, v.14, p.19-25, 1981.

ROSSETO, C.A.V.; FERNANDEZ, E.M.; MARCOS FILHO, J. Metodologias de ajuste do grau de umidade e comportamento das sementes de soja no teste de germinação. Revista Brasileira de Sementes, v.17, n.2, p.171-178, 1995.

SANCHEZ, V.M.; SUNDSTROM, F.J.; MCCLURE, G.N.; LANG, N.S. Fruit maturity, storage and posharvest maturation treatments affect bell pepper (Capsicum annuиm L.) seed quality. Scientia Horticulturae, v.54, n.3, p.191201, 1993.

SANTOS, C.M.R.; MENEZES, N.L.; VILLELA, F.A. Alterações fisiológicas e bioquímicas em sementes de feijão envelhecidas artificialmente. Revista Brasileira de Sementes, v.26, n.1, p.110-119, 2004.

TORRES, S.B. Envelhecimento acelerado em sementes de pimenta-malagueta (Capsicum frutescens L.). Revista Ciência Agronômica, v.36, n.1, p.98-104, 2005. 
VIDIGAL, D.S; DIAS, D.C.F.S.; PINHO, E..R.V.; DIAS, L.A.S. Sweet pepper seed quality and Lea-protein activity in relation to fruit and post-harvest storage. Seed Science and Technology, v.31, p.192-201, 2009a.
VIDIGAL, D.S; DIAS, D.C.F.S.; DIAS, L.A.S.; PINHO, E.R.V. Alterações fisiológicas e enzimáticas durante a maturação de sementes de pimenta. Revista Brasileira de Sementes, v.31, p.129-136, 2009b. 